\title{
Preparation and Characterizations of Composite Material Based on Carbon Fiber and Two Thermoset Resins
}

\author{
Hany Fouda ${ }^{1, a}$, Lin Guo ${ }^{1}$ and Karim Elsharkawy ${ }^{1}$ \\ ${ }^{1}$ Beihang University of Aeronautics and Astronautics, Beijing, china
}

\begin{abstract}
In the present investigation, we used two types of thermoset resins (epoxy resin and phenol formaldehyde resin) with carbon fiber (CF) to produce composite materials. CF/epoxy resin composite and $\mathrm{CF} /$ phenolformaldhyde resin composite were fabricated and compared between their mechanical properties as compression, tension and flexural. it was found that mechanical properties of CF/epoxy composite higher than mechanical properties of $\mathrm{CF} /$ phenolformaldhyde resin composite such as flexural strength of $\mathrm{CF} /$ epoxy resin composite increased by $30 \%$ than flexural strength of $\mathrm{CF} /$ phenolformaldhyde resin composite, tensile strength of $\mathrm{CF} /$ epoxy resin composite increased by $11.4 \%$ than flexural strength of $\mathrm{CF} /$ phenolformaldhyde resin and axial compression strength of $\mathrm{CF} /$ epoxy resin composite increased by $14.5 \%$ than flexural strength of $\mathrm{CF} /$ phenolformaldhyde resin.
\end{abstract}

\section{Introduction}

There is an increasing required for advanced materials with enhancement properties to meet new requirements or to replace existing materials. The carbon fibers have a unique combination of outstanding mechanical, physical and chemical properties, such as thermal resistance, high strength, and high modulus [1-3]. The carbon fibers reinforced resin matrix composites is widely used in aerospace, marine, and automobile industries during the past few decades due to their good engineering properties such as lower density, high specific strength and stiffness [1-5].Resin matrix of composites based on carbon fiber determines the thermal and chemical resistance of the composite while the carbon fibers provide strength and stiffness[4].

When a composite is subjected to stress, the load is transferred from the matrix to the carbon fibers through the interface and good interfacial bonding is therefore important. It is well known that the fiber matrix adhesion strength plays an essential role on the mechanical properties of fiber reinforced polymer composites because when a load applied to composites, it will be distributed and transferred through fiber/matrix interface [6-9]. A strong bonding promotes the better involvement of more fiber, accordingly increases the strength of composites. However, carbon fibers usually perform a poor adhesion or bonding behavior to polymer matrix due to their chemical inertness and nature of smoothness [6]. In order to improve the bonding properties of carbon fibers, various approaches can be applied, which were classified into oxidative and non-oxidative treatments according to Park and Kim [10]. Composite materials are being preferred more instead of steels and other metals because of their high strength at low a specific weight and also because composites have excellent resistance to

\footnotetext{
Corresponding author : hanyfouda@buaa.edu.cn
} 
chemicals, environment and corrosion so can be used in different environments and under various conditions [1-4]. Epoxy resins are considered as high-performance thermosetting resins, which display a unique combination of properties. Epoxy resins are one of the most versatile polymers with uses across an enormously wide variety of industries. They are composed of polymeric molecules that are converted to a solid by a chemical reaction. The ability to be transformed from a low-viscosity liquid (or thermoplastic state) into a tough, hard thermoset is the most valuable single property of epoxy resins.

An epoxy system physically comprises two essential components: a resin and a curative. The curative causes the chemical reaction, which turns the epoxy resin into a solid, cross linked network of molecules. This polymer is called a thermoset polymer structure with high cohesive strength and adhesion properties because, when cured, it is irreversibly rigid and relatively unaffected by heat. However, the term epoxy can also be used to indicate an epoxy resin thermoplastic or cured state.

Epoxy resin and phenolic resin are industrially very important polymeric materials that have vast application fields. The history of the two materials started before polymer science and polymer chemistry developed. Due to the tremendous efforts of many researchers involved in the materials, resin chemistry has been elucidated and novel approaches for highly functional and high-performance materials are being developed [10]. The increases in the use of the composite materials mean that it is very important and necessary to know their properties and behaviors under working conditions. Many researches applied on CF composite materials to improve their properties as research of Asma Yasmin, Isaac M. Daniel [11], research of Yuan Xu, Suong Van Hoa [12] and research of Farhana Pervin, Yuanxin Zhou, Vijaya K.Rangari, and Shaik Jeelani [13]

Many studies about the Composites have been carried out. When epoxy resins are reinforced with high strength carbon fibers, the obtained product is used in many commercial, military and structural applications requiring low weight and high strength. They are of relatively low density and they can be formed and tailored to have stacking sequences to produce high strength and stiffness in the directions of high loading [13-14].

In this work two types of thermoset resin used to produce two different types of CF composite materials. The first prepared composite sample was $\mathrm{CF} /$ Epoxy resin composite and the second prepared composite sample was $\mathrm{CF} /$ phenolformaldhyde resin composite in order to study the effect of the bonding force of the polymeric matrix into the properties of the prepared composite as mechanical properties as tension, compression, and flexural characteristics.

\section{Experimental work}

\subsection{Materials}

The carbon fiber used is PAN carbon fiber made from a polyacrylonitrile precursor has moderate strength; moderate modulus and carbon fiber yarn contains 3000 filaments obtained from Russia. The epoxy resin used in this study is a two component epoxy system consisting of (EPON 828) cured with polyamide (versamide 125) hardener. This two component system obtained from HEXION Company, France .epoxy processed in proportions of 1:1 by weight. Carbon fiber impregnated with phenol formaldehyde resin obtained from Russia.

\subsection{Preparation of epoxy samples}

Epoxy resin system consists of two parts A (EPON 828) and B hardener (versamide 125), part A was carefully weighed and stochemetric amount of part B was added, then stirring using magnetic stirrer for $30 \mathrm{~min}$ with low velocity to prevent air trapping [13]. 


\subsection{Composite fabrication}

Composite material based on CF/epoxy resin and was prepared by hand lay-up technique. Brush and roller were used to help the impregnation of fiber. The epoxy resin was prepared first as in the previous paragraph 2.2. The epoxy was brushed on the surface of CF. the epoxy-brushed fiber tape was carefully stacked up and aligned together layer above layer then compressed adding load $50 \mathrm{Kg}$ over the upper surface and left at room temp for $24 \mathrm{hrs}$ [11].composite material based on $\mathrm{CF} /$ phenolformaldhyde resin were prepared by the same way but differ in the last step because cured at elevated temp so put in a furnace at $150{ }^{\circ} \mathrm{C}$ under pressure 70 bar for $2 \mathrm{hrs}$.

\subsection{Mechanical testing}

In this research, two types of mechanical testing machines were used. The first test machine is MTS810 Servo-hydraulic material test system with100 KN axial loading was applied to investigate tensile modulus and strength. The second test machine is RT30 Electro-mechanical Alliance test system with $30 \mathrm{KN}$ axial loading applied to measure both flexural and compression strength .the two machine systems were obtained from MTS Company, United States.

\subsection{1 compression test}

The compression strength of composite specimen of dimensions [10 $\mathrm{mm} \times 10 \mathrm{~mm} \times 20 \mathrm{~mm}]$ was tested. The test speed was kept const at $2 \mathrm{~mm} / \mathrm{min}$. Three specimens of each composition were measured and an average value was reported. In the case of composite we measured compression strength in both directions (axial and radial directions) as shown in figure 1.

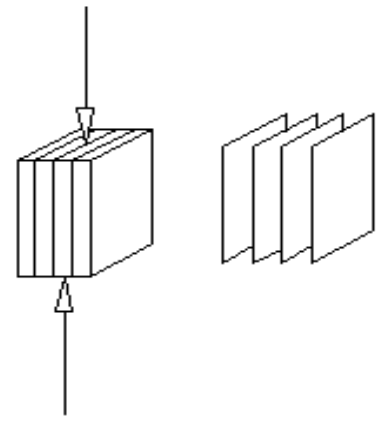

Axial

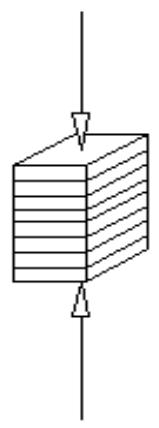

Radial

Figure 1. Axial and radial compression specimens for composite material.

\subsubsection{Flexural test (the three-point bending test)}

The Flexural strength is the maximum stress developed when a bar - shaped specimen is subjected as a single beam to a bending force perpendicular to the bar. The Flexural strength of composite specimen of $12.7 \mathrm{~mm}$ width, $200 \mathrm{~mm}$ length and thickness according to the number of layers. Three specimens of each composition were measured and an average value was reported. 


\subsubsection{The tensile test}

The tensile strength of composite specimen of $12.7 \mathrm{~mm}$ width, $203 \mathrm{~mm}$ length and thickness according to the number of layers. Three specimens of each composition were measured and an average value was reported. The standard shape and dimensions for the tensile test samples and flexural test samples shown in figure 2.

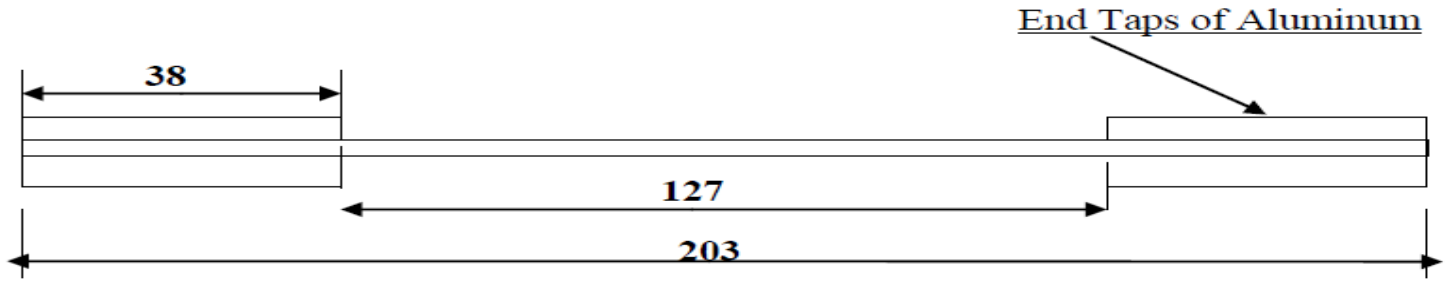

Figure 2. Standard Flat Tensile and flexural specimens.

\subsection{Thermal conductivity measurements}

Thermal conductivity values are used to measure heat flow through a material according to the apparatus specifications of lee ś disk method used in determination of thermal conductivity of bad conductor, the specified specimens were found to take the form of a thin disc with one side of it is heated by being placed in contact with a metallic steam chamber and the other side is in contact with a cylindrical brass calorimeter which is used for measuring the quantity of heat conducted to it per second as shown in figure 3.

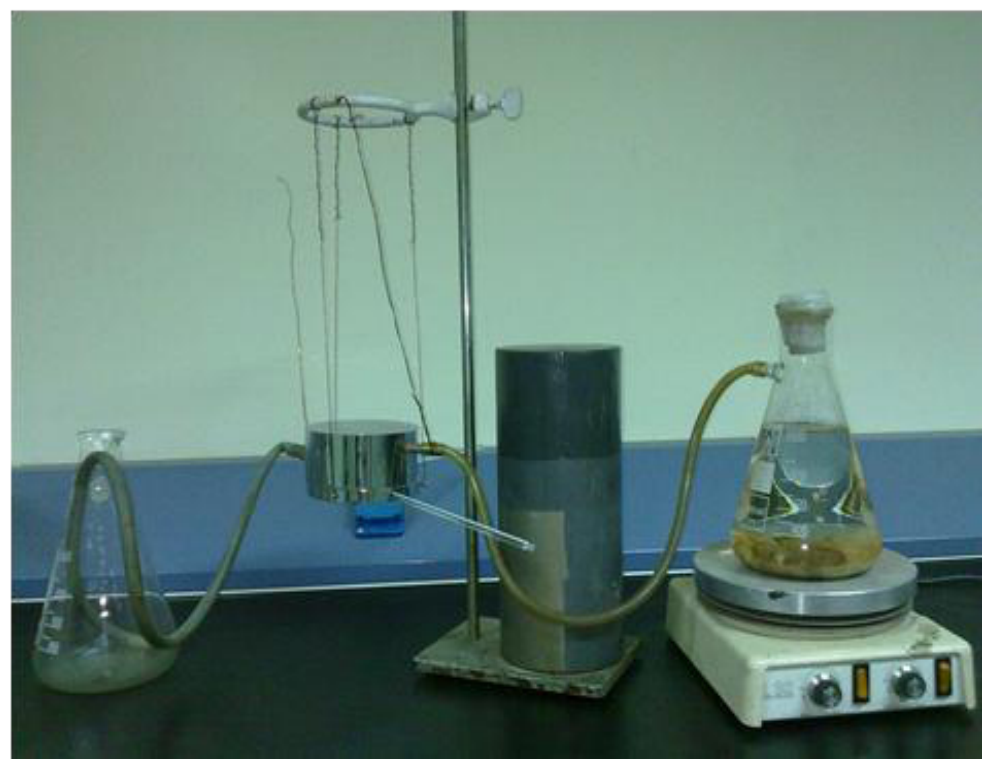

Figure 3. Thermal conductivity measurement apparatus.

The test was carried out according to the following steps:

1. The specimen is placed between the steam chamber and the calorimeter.

2. Heat in the form of steam flows from the higher temperature (steam chamber) to lower one (calorimeter) for a sufficiently long time ( 45-60 minutes) until the thermometers give constant 
reading for the temperature of steam chamber and that of the calorimeter denoted by $(\Theta 1$ and $\Theta 2)$ respectively, then the specimen is removed.

3. The calorimeter with steam chamber on it is heated to about $5^{\circ} \mathrm{C}$ above the steady temperature $\mathrm{\theta} 2$, and then the steam chamber is replaced by the specimens allowing for the calorimeter to cool to a temperature lower $5{ }^{\circ} \mathrm{C}$ below the steady temperature $\Theta 2$.

-Rate of heat loss by the calorimeter and specimen is calculated according to the following formula: $\mathrm{Q}=\mathrm{m} * \mathrm{~s} *(\mathrm{~d} \Theta / \mathrm{dt})$

- Rate of conducting of heat $=\mathrm{K}^{*} \mathrm{~A} *(\Theta 1-\Theta 2) / \mathrm{X}$

-Thus at steady state: $\mathrm{K} * \mathrm{~A} *(\Theta 1-\Theta 2) / \mathrm{X}=\mathrm{m} * \mathrm{~s} *(\mathrm{~d} \Theta / \mathrm{dt})$

Where:

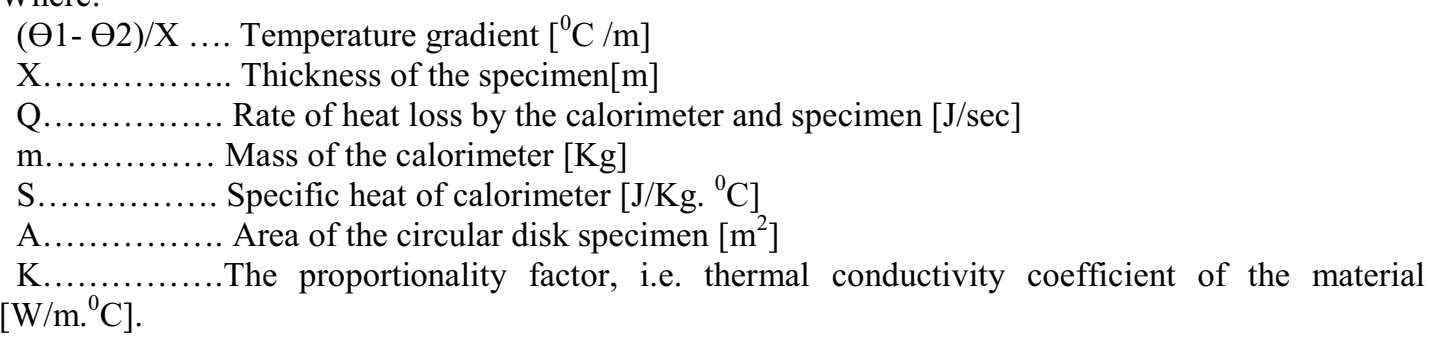

\subsection{Samples code and Compositions}

The code and composition of the prepared composite samples used in this research illustrated in table 1.

Table 1. Details of composition of each formulation

\begin{tabular}{|l|l|}
\hline Formulation code & Composition \\
\hline C1 & 8layers[CF+ epoxy resin] \\
\hline C2 & 8 layers[CF+ phenol formaldehyde resin] \\
\hline
\end{tabular}

\section{Result and discussion}

\section{1 mechanical properties}

\subsubsection{Tensile test result}

The tensile properties of prepared composite materials are shown in figure 4. The figure shows that there are two composite samples based on CF and have the same number of CF layers. The composite sample $\mathrm{C} 1$ is based on $\mathrm{CF} /$ epoxy resin and the second composite sample $\mathrm{C} 2$ is based on $\mathrm{CF} /$ phenolformaldhyde resin. The results show that the tensile strength of composite materials based on CF/epoxy resin is higher than the tensile strength of composite materials based on $\mathrm{CF} /$ phenolformaldhyde resin by $11.4 \%$ respectively. This is because the adhesion force of epoxy resin is higher than that of phenolformaldhyde resin, so the composite material based on $\mathrm{CF} /$ epoxy resin matrix has higher tensile strength than that based on $\mathrm{CF} /$ phenolformaldhyde resin matrix. 


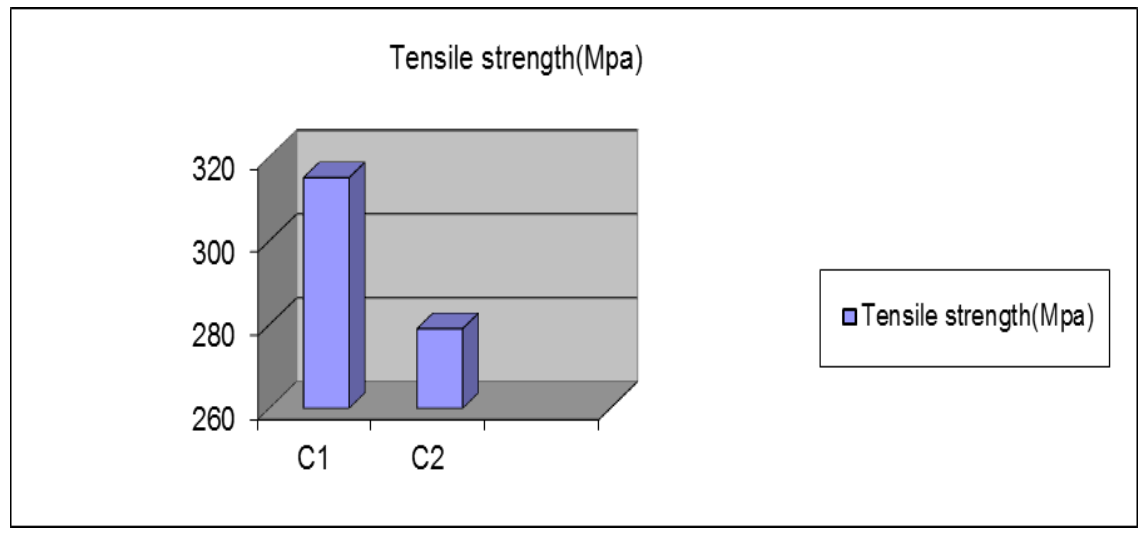

Figure 4. Tensile strength of CF/epoxy resin composite and CF/phenolformaldhyde resin composite.

\subsubsection{Flexural test result}

The flexural properties of the prepared composite samples are shown in figure 5. The figure shows two composite samples based on CF having the same number of layers. The first composite sample is $\mathrm{C} 1$ and is based on CF/epoxy resin. The second composite sample $\mathrm{C} 2$ is based on $\mathrm{CF} /$ phenolformaldhyde resin.

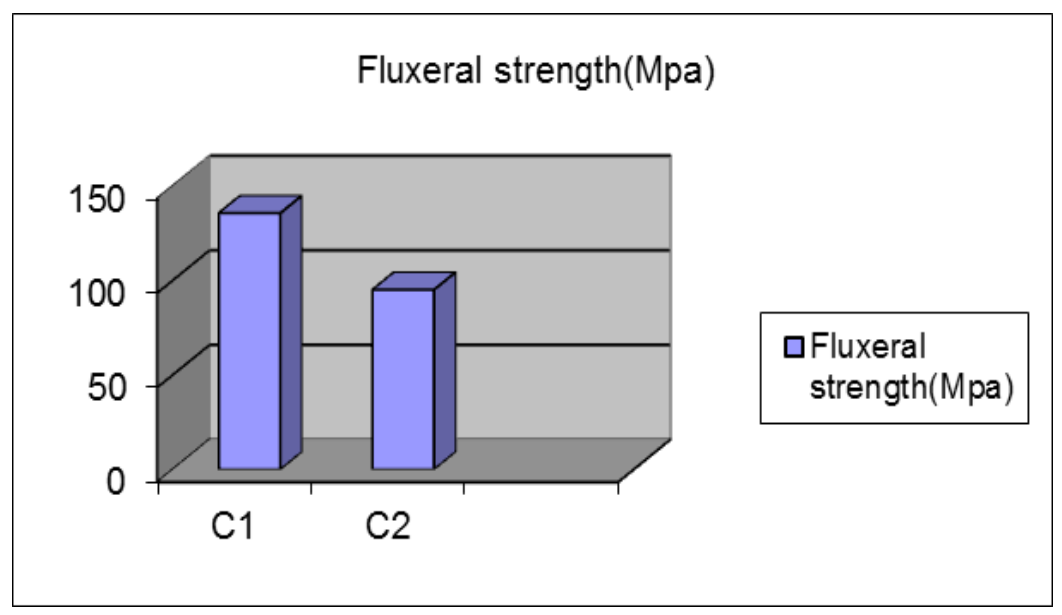

Figure 5. Flexural strength of $\mathrm{CF} /$ epoxy resin composite and $\mathrm{CF} /$ phenolformaldhyde resin composite.

From figure 5, it can be seen that the flexural strength of composite material based on CF/epoxy resin are higher than those based on $\mathrm{CF} /$ phenolformaldhyde resin by $30 \%$. This is because the adhesion force of epoxy resin is higher than that of phenolformaldhyde resin.

\subsubsection{Compression test result}

The compression properties of the prepared composite samples are shown in figure 6 and figure 7 . The figures show two composite samples based on CF and have the same number of CF layers. The 
first composite sample $\mathrm{C} 1$ is based on $\mathrm{CF} /$ epoxy resin and the second composite sample $\mathrm{C} 2$ is based on $\mathrm{CF} /$ phenolformaldhyde resin.

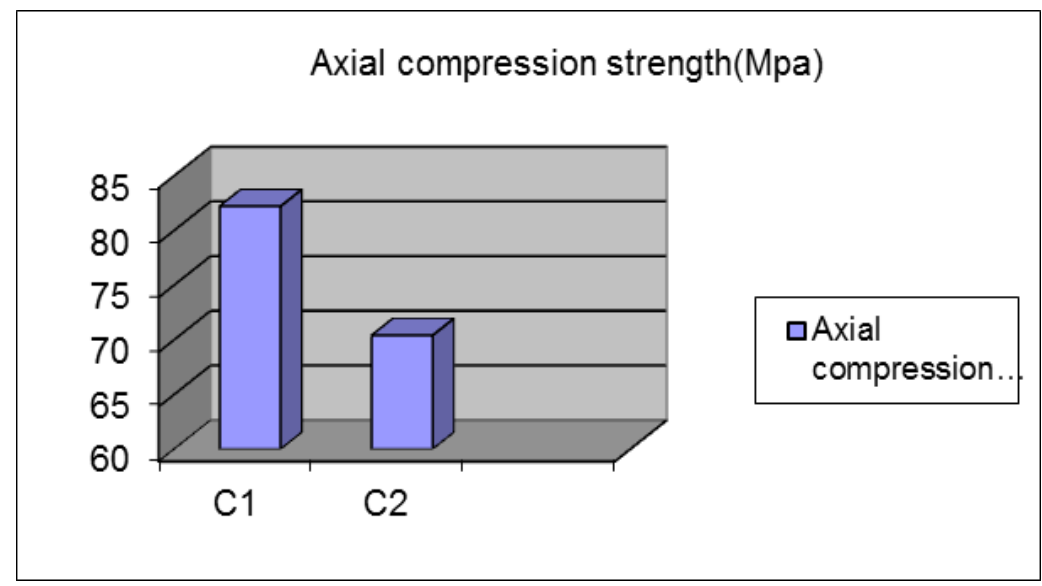

Figure 6. Axial compression strength of $\mathrm{CF} /$ epoxy resin composite and $\mathrm{CF} /$ phenolformaldhyde resin composite.

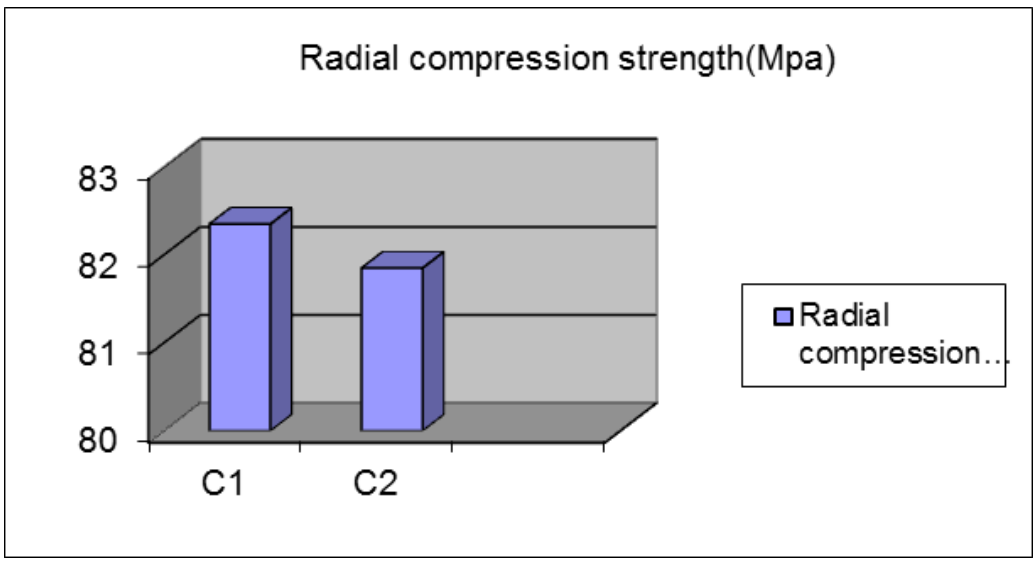

Figure 7. Radial compression strength of $\mathrm{CF} /$ epoxy resin composite and $\mathrm{CF} /$ phenolformaldhyde resin composite.

Figure 6 shows that axial compression strength of $\mathrm{C} 1$ is higher than that of $\mathrm{C} 2$ by $14.5 \%$. This is because in the case of axial compression the compression strength depends on adhesion force of resin. The adhesion force of epoxy resin is higher than that of phenolformaldhyde resin. Figure 7 shows that radial compression strength of $\mathrm{C} 1$ is nearly the same as that of $\mathrm{C} 2$. This is because radial compression strength depends on fiber type, not resin type which is the same in the two samples.

\subsection{Thermal conductivity results}

Thermal conductivity results for prepared composite material samples are shown in table 2 . From the results, thermal conductivity values show that the thermal conductivity of $\mathrm{C} 1<\mathrm{C} 2$. The Thermal conductivity of $\mathrm{C} 1$ is less than that of $\mathrm{C} 2$. 
Table 2. Thermal conductivity for different prepared composite materials.

\begin{tabular}{|l|l|}
\hline \multicolumn{1}{|c|}{$\begin{array}{c}\text { Characteristics } \\
\text { Sample code }\end{array}$} & $\begin{array}{l}\text { Thermal } \\
\text { conductivity }\left(\mathrm{W} / \mathrm{m} .{ }^{0} \mathrm{C}\right)\end{array}$ \\
\hline $\mathrm{C} 12$ & 0.1253 \\
\hline $\mathrm{C} 2$ & 0.232 \\
\hline
\end{tabular}

\section{Conclusion}

Resin matrix can be used as one of the most common and effective matrix with carbon fiber to synthesis composite materials based on CF and resin matrix. It was found that as the adhesion bond of the resin matrix increase the mechanical properties of prepared composite increase. Two types of composite materials based on $\mathrm{CF}$ were prepared $\mathrm{CF} /$ Epoxy resin matrix composite and $\mathrm{CF} /$ phenolformaldhyde resin matrix composite. It was found that the mechanical properties of $\mathrm{CF} /$ epoxy resin composite higher than that of $\mathrm{CF} /$ phenolformaldhyde resin composite due to the higher adhesion force of epoxy resin than phenolformaldhyde resin. For example the tensile strength, flexural strength and axial compression strength of $\mathrm{CF} /$ epoxy resin composite is higher than that of $\mathrm{CF} /$ phenolformalhyde resin composite by $11.4 \%, 30 \%$ and $14.5 \%$ respectively.it was also found that the thermal conductivity of $\mathrm{CF} /$ epoxy resin composite is lower than that of $\mathrm{CF} /$ phenolformaldhyde resin composite.

\section{References}

1. Schwartz MM," composite materials hand book" , McGraw-Hill; 1992.

2. Whitcomb JD, "Composite materials testing and design", ASTM; 1988.

3. S.T.Peters, "Hand book of composite", CHAPMAN\&HALL; 1998.

4. Deborah D. L.Chung, "Carbon Fiber Composites, Butterworth-Heinemann; 1994.

5. Ronald F.Gipson,"Principles of composite materials mechanics ", McGraw-Hill.

6. Hui Zhang, Zhong Zang, Claudia Breidt, "Comparison of short carbon fiber surface treatments on epoxy composites", institute for composite materials, university of Kaiserslautern, Erwin Schrodinger strasse 58; 2004.

7. Park BY, Kim SC, "A study of the interlaminer fracture toughness of a carbon-fiber/epoxy composite containing surface modified short Kevlar fiber", Compos sci technol; 1998.

8. Fux, Chung DDL, "Improving the bond strength between carbon fiber and cement by fiber surface treatment and polymer addition to cement mix", Cement concrete Res; 1995.

9. Dong S, Gauvin R," Application of dynamic mechanical analysis for the study of the interfacial region in carbon fiber/epoxy composite materials ", Polym compos, 1993.

10. T. Takeichi, N. Furukawa, "Epoxy Resins and Phenol-Formaldehyde Resins", Reference Module in Materials Science and Materials Engineering Polymer Science: A Comprehensive Reference, pages 723-751, volume 5, 2015.

11. Asma Yasmin, Isaac M. Daniel, "Mechanical and thermal properties of graphite platelet/epoxy composites", Northwestern University, Evanston; 2004.

12. Yuan $\mathrm{Xu}$, Suong Van Hoa, "mechanical properties of carbon fiber reinforce epoxy/clay nanocomposites", center for research in polymer and composites, Canada; 2007.

13. Farhana Pervin, Yuanxin Zhou,Vijaya K.Rangari,Shaik Jeelani, "Testing and evaluation on the thermal and mechanical properties of carbon nano fiber reinforced SC-15 epoxy", Center of advanced material, Tuskegee; 2005.

14. J.B. Donnet, compos.Sci. Technol, 63(2003) 1085-1088. 